\title{
Duration of breastfeeding, age at introduction of complementary foods and allergy-related diseases: a prospective cohort study
}

\author{
Louise Ekelund $^{1 \dagger}$, Inga Gloppen ${ }^{1 \dagger}$, Torbjørn Øien ${ }^{2}$ and Melanie Rae Simpson ${ }^{2,3^{*}}$ (D)
}

\begin{abstract}
Background: The influences of breastfeeding and infant diet in the prevention of allergy-related diseases are uncertain and many of the studies conducted on the topic are limited by methodological challenges. Our aim was to assess whether the duration of breastfeeding and age at complementary food introduction affected the prevalence of asthma, wheeze, allergic rhinoconjunctivitis (ARC) and eczema at two and six years of age.

Methods: We used information gathered between 2000 and 2014 through questionnaires in the Prevention of Allergy among Children in Trondheim (PACT) study, a prospective cohort study in Trondheim, Norway. The current study includes 6802 children who submitted questionnaires detailing breastfeeding duration and or age at introduction to complementary foods, as well as at least one of the child health questionnaires completed at two and six years of age. Adjusted odds ratios (aORs) were calculated for each combination of exposure and outcomes and sensitivity analyses were performed to assess the possible influence of recall bias and reverse causality.
\end{abstract}

Results: The mean duration of breastfeeding was 11 months (SD 5.6) in this study population and 5695 of 6796 (84\%) infants had been breastfed for at least 6 months. We did not find any conclusive preventative effect of longer breastfeeding on parental reported doctor-diagnosed asthma, aOR 0.79 (95\% Cl 0.51, 1.21). However, at 6 years of age we observed a reduction in the less strictly defined outcome wheeze, aOR $0.71(95 \% \mathrm{Cl} 0.53,0.95)$. Longer breastfeeding was associated with a reduced risk of ARC at 2 years, aOR $0.65(95 \% \mathrm{Cl} 0.49,0.86)$, with a continued protective trend at 6 years, aOR $0.77(95 \% \mathrm{Cl} 0.58,1.04)$.

Conclusions: Longer breastfeeding resulted in a reduced risk of wheeze and a trend towards a protective effect on ARC up until school age. No conclusive associations were seen between the duration of breastfeeding or age at introduction to complementary foods and prevention of asthma, wheeze, ARC and eczema.

Trial registration: The trial is registered in Current Controlled Trials as ISRCTN28090297.

Keywords: Breastfeeding, Complementary food, Allergy, Asthma, Wheeze, Eczema, Allergic rhinoconjunctivitis, Prevention

\footnotetext{
* Correspondence: melanie.simpson@ntnu.no

${ }^{\dagger}$ Louise Ekelund and Inga Gloppen share joint first authorship, these authors have contributed equally to this work.

${ }^{2}$ Department of Public Health and Nursing, Norwegian University of Science and Technology, NTNU, Trondheim, Norway

${ }^{3}$ Clinic of Laboratory Medicine, St Olavs Hospital, Trondheim, Norway

Full list of author information is available at the end of the article
}

C The Author(s). 2021 Open Access This article is licensed under a Creative Commons Attribution 4.0 International License, which permits use, sharing, adaptation, distribution and reproduction in any medium or format, as long as you give appropriate credit to the original author(s) and the source, provide a link to the Creative Commons licence, and indicate if changes were made. The images or other third party material in this article are included in the article's Creative Commons licence, unless indicated otherwise in a credit line to the material. If material is not included in the article's Creative Commons licence and your intended use is not permitted by statutory regulation or exceeds the permitted use, you will need to obtain permission directly from the copyright holder. To view a copy of this licence, visit http://creativecommons.org/licenses/by/4.0/. The Creative Commons Public Domain Dedication waiver (http://creativecommons.org/publicdomain/zero/1.0/) applies to the data made available in this article, unless otherwise stated in a credit line to the data. 


\section{Background}

The prevalence of allergy-related diseases, such as asthma, allergic rhinoconjunctivitis (ARC) and eczema, increased substantially in the second half of the twentieth century. Together, these diseases are the most common noncommunicable diseases among children worldwide [1]. Whilst the prevalence varies widely between counties, we tend to find higher rates of these diseases in developed countries. In Europe, the reported cumulative incidence of asthma, ARC and eczema at 8 years of age is around 15, 16 and 34\%, respectively [2]. These allergy-related diseases often appear to share some common pathophysiological pathways, and children who are also sensitised to common allergens are at a greater risk of other allergy-related diseases [2, 3]. Both genetic and environmental factors are thought to contribute to the complex aetiology of these diseases [4].

The influence of the duration and exclusivity of breastfeeding on allergy-related diseases has been widely debated for decades. While the primary role of breast milk is to nourish and hydrate newborn infants, it also provides a direct immune defence against pathogens, decreasing the risk of respiratory and gastrointestinal infections in infants [5].

Whilst many studies have reported a protective effect of breastfeeding on allergy-related diseases, others have found that it may even increase the risk of these diseases. Overall, two recent meta-analyses found a reduced risk of the composite outcome asthma/wheeze with longer breastfeeding $[6,7]$, a possible reduction in the risk of ARC [7] and no apparent effect on the risk of eczema $[6,7]$. As highlighted by these meta-analyses, the conflicting results of the original studies are likely due to a combination of the methodological challenges in breastfeeding research, and further complicated by the variations in how breastfeeding exposure and the allergyrelated outcomes are defined. In likeness with many observational studies, the internal validity of research into breastfeeding is threatened by the risk of reverse causality, recall bias of breastfeeding exposure and incomplete adjustment for confounding factors [7]. The systematic review and meta-analysis by Garcia-Larsen et al. further emphasised the problem with publication bias, and estimated that the lack of control for confounding alone accounted for a high risk of bias in $30-35 \%$ of all included studies [6]. Additionally, there is heterogeneity in definitions used for the allergy-related diseases, and the stringency of these definitions may influence the apparent effect of breastfeeding. For example, the definition of asthma varies widely from parental reported wheeze to an asthma diagnosis after a physician examination [6-11].

More recently, the impact of age of introduction to complementary foods on allergy-related diseases has also been debated. Randomised controlled trials have produced some promising results for early introduction of peanut and egg in high risk infants to prevent food allergy to these specific allergens $[12,13]$. However, it is uncertain if the timing of introduction to complementary foods, in general, influences the development of allergy-related disease. This was investigated in a recent systematic review by Obbagy et al. [14], which concluded that there is no certain relationship between the age of complementary food introduction and asthma, eczema or food allergies. They had insufficient studies to assess the relationship for ARC. This systematic review also emphasised that many of the included studies suffered from the same methodological challenges faced by studies investigating the effect of breastfeeding $[6,11,14]$. As such, a larger prospective cohort study that attempts to address these limitations is warranted for both breastfeeding and age of complementary food introduction.

In the current study, we have used data from the Prevention of Allergy among Children in Trondheim (PACT) study. Our aim was to examine the associations between the duration of breastfeeding, the age of introduction to complementary foods, and the allergy related outcomes, asthma, wheeze, ARC and eczema, at two and six years of age.

\section{Methods}

Prevention of allergy among children in Trondheim study This is a substudy of the PACT study and is based on all children for whom we have data on breastfeeding duration or complementary food introduction and allergyrelated disease at two or six years. The main PACT study was a controlled, prospective cohort study of pregnant women and their children in primary healthcare in Trondheim, Norway. The PACT study aimed to reduce the incidence of allergy-related diseases among children through lifestyle recommendations given to pregnant women and families of young children [15]. The recommendations included in the intervention were to reduce tobacco exposure, reduce housing dampness and mould, and to increase maternal and infant intake of fatty fish and cod liver oil. The introduction of fish was recommended as dinner and sandwich spread from when the child was six months of age [16]. After the intervention commenced, these recommendations were given to all expecting families, as a public health strategy, regardless of whether they were participating in the study or not. No aspect of the intervention was aimed at breastfeeding, formula feeding or the timing of complementary foods introduction [15].

Throughout the PACT study, the national recommendations in Norway were exclusive breastfeeding for the first six months of life, with introduction of complementary foods at six months together with continued breastfeeding up to one year of age [16]. This is in line with 
the current recommendations from the World Health Organization, except that their advice includes continued breastfeeding up to two years of age or beyond [17].

\section{Study design and participants}

Participating families were recruited at routine prenatal and child health follow-ups at general practices and community health centres throughout Trondheim [15]. All seven community-based midwives, all 20 maternity health centres, and 32 of 35 general practices in Trondheim participated. Socio-demographic characteristics and relevant risk factors were obtained from up to four lifestyle questionnaires completed during pregnancy and when the child was six weeks, one year and two years old. In addition, child health questionnaires, focusing primarily on signs and symptoms of allergy-related disease, were completed when the child was two and six years old. Inclusion to the PACT study commenced in 2000 with recruitment of pregnant women, as well as 6week, 1-year, 2-year and 6-year-old children. The inclusion period for pregnant women ended in 2006 and the last 6-year-old questionnaires were completed in 2014. During the inclusion period there were approximately 2150 deliveries per year in Trondheim [18], however we do not have accurate information about how many families chose not to participate in the PACT study. The questions regarding allergy-related diseases were adapted from the International Study of Asthma and Allergies in Childhood (ISAAC) questionnaire with adjustment made to suit the age group and were previously assessed in a reliability study conducted by the PACT research group [19]. The current study consists of all children whose family had completed at least one lifestyle questionnaire, including information on breastfeeding or introduction of first complementary food, and at least one child health questionnaire (Fig. 1).

\section{Outcome variables}

The studied outcomes were asthma, wheeze, ARC and eczema in children at two and six years of age. While asthma and ARC are considered as more defined diseases at six years, the peak prevalence of eczema occurs at a younger age (18-21). Therefore, a cumulative prevalence of eczema at six years of age was calculated to assess the effect of breastfeeding and complementary food on the risk of eczema at any time up to six years. The outcomes were defined according to the answers in the child health questionnaires (Table 1). To be able to compare these results to studies with different outcomes definitions, this study included both the parental reported doctor-diagnosed asthma, and parental reports of symptoms of wheeze.



Fig. 1 Flow chart of participants 
Table 1 Outcome variables as defined based on questionnaires

\begin{tabular}{|c|c|c|}
\hline $\begin{array}{l}\text { Allergy-related } \\
\text { condition }\end{array}$ & $\begin{array}{l}\text { Time } \\
\text { point(s) }\end{array}$ & Questions used to define cases \\
\hline Asthma (ever) & 2 years & "Has the child ever been diagnosed with asthma by a doctor" \\
\hline Asthma (current) & 6 years & $\begin{array}{l}\text { As asthma (ever) AND "Has the child been treated with tablets, inhalation medications or other treatments for } \\
\text { wheezing, tightness in the chest or asthma during the last } 12 \text { months? }\end{array}$ \\
\hline Wheeze (ever) & 2 years & $\begin{array}{l}\text { "Has the child ever had whistling in the chest?" AND "Has the child ever had episodes of wheezing or tightness } \\
\text { in the chest? }\end{array}$ \\
\hline Wheeze (current) & 6 years & As for wheeze (ever) AND "Has the child had whistling, rattling or tightness in the chest in the past 12 months? \\
\hline ARC (ever) & $2 \& 6$ years & "Has the child ever had hay fever, sneezing or itchy-watery eyes? \\
\hline Eczema (ever) & $2 \& 6$ years & $\begin{array}{l}\text { "Has the child ever had eczema?" AND "Has the child ever had an itchy rash which came and went over at least } \\
\text { six months? }\end{array}$ \\
\hline Eczema (current) & 6 years & $\begin{array}{l}\text { As for eczema (ever) AND "Has the child during the last } 12 \text { months used medications, balms, creams, tablets or } \\
\text { herbal medicines for eczema? }\end{array}$ \\
\hline
\end{tabular}

The age of onset of the different outcomes was also recorded in order to account for reverse causality, except for wheeze where the questionnaires did not provide such data.

\section{Exposure variables}

The aim of this study was firstly to investigate whether the duration of breastfeeding had any effect on the development of asthma, wheeze, ARC or eczema. We defined breastfeeding as any breastfeeding, regardless of whether the child had been introduced to any solids or formula. A cut-off at six months divided the participants into two groups: those who had been breastfed six months or more, and those breastfed less than six months. This information was collected from the lifestyle questionnaires completed at six weeks, one year and two years. At each of these time points, participating families were asked if the child ever had received breast milk and if they had been weaned and at what age. The information on breastfeeding duration was collected from the closest available questionnaire, with respect to age of weaning, and resulted in a maximum recall from six weeks to two years.

Subsequently, we studied the risk of developing allergy-related diseases with respect to age at introduction of complementary foods. Participating families were asked about the age at which the child had been introduced to porridge (rice, corn and wheat), boiled and raw vegetables, fruits, commercial or homemade dinners, fish, cow's milk, and egg. The time of introduction to complementary foods was defined as the earliest age (in months) the child had started with any of the mentioned dietary options. Based on this age, the children were categorised into two groups: those introduced at six months of age or later, and those introduced before six months of age. This information was obtained from the lifestyle questionnaire completed when the child was one year old and resulted in a maximum recall of one year. Finally, we analysed if a period of overlap between breastfeeding and nourishment with complementary foods had any effect on the development of allergyrelated diseases. A minimum of two months overlap was used to distinguish the two groups.

\section{Statistics}

All statistical analyses were conducted using Stata/MP 15 (StataCorp, College Station, Texas). Univariable logistic regression was used to obtain crude odds ratios (ORs) for each studied exposure and outcome. Potential confounders were identified a priori and examined in multivariable analyses before determining a final model and the results are presented as adjusted odds ratios (aORs). Statistical significance was assessed using 95\% CIs. In sensitivity analyses, we considered the potential effects of recall bias and reverse causality on our results and examined if the relationship between longer breastfeeding duration and allergy-related diseases may be modified by the introduction of formula before six months. First, the breastfeeding analyses were repeated in the subgroup of families with maximum of one-year recall for age of weaning. Second, all analyses were repeated after exclusion of children reported to have developed symptoms of any of the allergy-related diseases before six months of age. Third, we separated the group which reported any breastfeeding for at least six months into those who had or had not introduced infant formula before six months of age and compared each of these subgroups to children who were weaned before six months.

In all analyses, we considered the following covariates as possible confounders: gender, maternal age, older siblings, first degree relative with allergy, maternal smoking during the child's first two years, birthweight, and socioeconomic status (SES). Ultimately, the mean income of the family's postcode of residence presence was used as an indicator of SES and the presence of older siblings was excluded from the final models as described below. Information regarding covariates were collected from 
the lifestyle questionnaires, except for mean income, which was gathered from the Norwegian assessment roll from 2009 [20].

There is no single best indicator of SES [21] and we found the average income in the postcode of residence to be the most appropriate alternative in the current study. Other indicators of SES collected in the PACT study were homeownership and parental level of education. The former provided poor discrimination of SES due to the high proportion of homeownership in Trondheim, and the latter was subject to a large proportion of missing data because information on parental level of education was not collected throughout the entire study period. Before using the average income of the postcode of residence in our analyses, we conducted a number of tests to examine its suitability. We confirmed that it corresponded well with other variables commonly associated with SES, such as parental smoking behaviour, maternal age and homeownership (Suppl. Table 1, Additional File 1). Since parental education did not demonstrate a clear association with the average income of postcode of residence, we investigated the effect of including either or both variables as covariates in our analyses. In order to do this we ran parallel logistic regression models and confirmed that the estimated associations between breastfeeding or introduction to complementary food and the allergy-related diseases were near identical regardless of whether we adjusted for average postcode income or maternal education level in the subgroup of participants with information on both SES indicators $(n=1669$ to 2156 depending on which allergy-related outcome data not shown). In order to maintain a parsimonious model, the following variables were not included as covariates in the final models after preliminary analyses: the presence of older siblings, exposure to paternal smoking and household pets in the first year of life, and day-care attendance before one year of age. The presence of older siblings was not excluded because it did not significantly affect the results when included as a covariate and we did not have this information for a high proportion of the children. Since parental smoking was highly correlated with maternal smoking, we opted to include only the latter. Exposure to household pets was excluded because it was considered unlikely to be a substantial confounding factor and we observed that it did not significantly alter the regression results when included as a covariate. Similarly, we saw little indication that day-care attendance before one-year was associated with breastfeeding or introduction to complementary foods at six months in our population and this was not included as a covariate in the models. Respiratory tract infections and antibiotic use were considered potential mediators of the effect of breastfeeding on allergy-related diseases and not included in the regression models.

\section{Results}

The PACT study includes over 20,000 children, however nearly half of these families were recruited when the children were 6-years-old such that for 9848 children we had no information from the lifestyle questionnaires due to the design of the study. In total, 6802 children could be included in this current study, of which 6103 and 3708 had completed the child health questionnaire at two and six years, respectively (Fig. 1). In addition to those who were missing the lifestyle questionnaires, 2339 and 1364 could not be included due to missing information on the exposures or outcomes, respectively. We do not have further information on reasons for nonparticipation or loss to follow up. However, a previous non-participant study showed a tendency of lower prevalence of parental smoking and proportion of with family history of allergy-related disease in the PACT population, but none of these differences were statistically significant [15].

The mean age of the children at the two follow up points were 2.5 years (range 1.7-3.0 years) and 6.4 years (range 5.6-7.5 years). The prevalence of each of the studied allergy-related diseases at two and six years are presented in Table 2. Characteristics of families included in analyses of breastfeeding duration and timing of complementary food introduction are presented in the relevant sections, below. Families excluded from the current analyses due to missing child health questionnaire data reported a shorter breastfeeding duration and a higher percentage of formula supplemented children compared to those included in the current study. In this group, there was a lower proportion with older siblings, furry pets, antibiotic treatment within the first year of life, and

Table 2 Prevalence of allergy-related diseases

\begin{tabular}{lllll}
\hline Disease and age & $\boldsymbol{N}^{*}$ & $\boldsymbol{n}$ & $\mathbf{\%}$ & $\mathbf{9 5 \% ~ C l}$ \\
\hline Asthma & & & & \\
$\mathbf{2}$ years (ever) & 6101 & 403 & 6.6 & $6.0,7.3$ \\
$\quad \mathbf{6}$ years (current) & 3705 & 175 & 4.7 & $4.1,5.5$ \\
Wheeze & & & & \\
$\mathbf{2}$ years (ever) & 5922 & 1577 & 26.6 & $25.5,27.8$ \\
$\quad \mathbf{6}$ years (current) & 3668 & 388 & 10.6 & $9.6,11.6$ \\
ARC & & & & \\
$\mathbf{2}$ years (ever) & 5562 & 354 & 6.4 & $5.8,7.0$ \\
$\mathbf{6}$ years (ever) & 3438 & 424 & 12.3 & $11.3,13.5$ \\
Eczema & & & & \\
$\mathbf{2}$ years (ever) & 5927 & 998 & 16.8 & $15.9,17.8$ \\
$\mathbf{6}$ years (current) & 3648 & 505 & 13.8 & $12.8,15.0$ \\
$\mathbf{6}$ years (ever) & 3630 & 710 & 19.6 & $18.3,20.9$ \\
\hline
\end{tabular}

${ }^{*}$ Children with available information on duration of breastfeeding or age at introduction to complementary foods are included. The numbers vary because of missing outcome data 
reported family history of allergy-related disease (Supplementary Table S2, Additional File 1).

\section{Breastfeeding duration}

For the 6796 children with available information on breastfeeding, the mean duration of breastfeeding was 11 months (SD 5.6) and 5670 (84\%) had been breastfed for six months or more. A longer duration of breastfeeding was positively associated with older mothers, and parents with higher education and who lived in areas with higher mean income (Table 3). The duration of breastfeeding was also strongly correlated to parents smoking habits, and children who were breastfed longer were more likely to have non-smoking parents. Additionally, they were less likely to have been born with low birthweight.

As would be expected, we also observed that children who were breastfed for more than six months tended to receive less infant formula (Table 3 ). In the subgroup of infants with information on both breastfeeding duration and complementary food introduction age $(n=3808)$, we found that only $993(26 \%)$ of families waited until six months before introducing complementary foods, regardless of breastfeeding duration. However, those families who breastfed for less than six months was substantially less likely to delay complementary food introduction until six or later months with only 60 of 606 (10\%) families falling into this category (Suppl. Table S3, Additional File 1).

\section{Breastfeeding and allergy-related disease}

When assessing the relationship between breastfeeding for at least six months and allergy-related disease, the crude ORs suggested a statistical association between longer breastfeeding and a lower cumulative incidence of both asthma and wheeze at two years, as well as a lower prevalence of current wheeze at six years of age (Table 4). After adjusting for possible confounding, longer breastfeeding duration was still associated with lower cumulative incidence of asthma and wheeze at two years

Table 3 Characteristics of the participants stratified according to duration of breastfeeding

\begin{tabular}{|c|c|c|c|c|}
\hline \multirow{3}{*}{ Characteristics } & \multicolumn{4}{|c|}{ Duration of any breastfeeding $(N=6796)$} \\
\hline & \multicolumn{2}{|c|}{$\geq 6$ months $(n=5695)$} & \multicolumn{2}{|c|}{$<6$ months $(n=1101)$} \\
\hline & $n^{\mathrm{a}}$ & & $n^{\mathrm{a}}$ & \\
\hline Maternal age at birth, years, mean (SD) & 5670 & 30.2 (4.4) range: $16.8-44.5$ & 1095 & 28.7 (5.1) range: $17.0-44.2$ \\
\hline Maternal education, $n(\%)$ & 2625 & & 392 & \\
\hline$<12$ years (less than high school) & & $116(4.4)$ & & $62(15.8)$ \\
\hline $12-16$ years (up to 4 years university) & & $1298(49.5)$ & & $237(60.5)$ \\
\hline$>16$ years (more than 4 years university) & & $1211(46.1)$ & & $93(23.7)$ \\
\hline Mean income ${ }^{\mathrm{b}}$, NOK, mean (SD) & 5465 & $255,414(29175)$ & 1053 & $250,191(30405)$ \\
\hline Family history of allergy ${ }^{c}, n(\%)$ & 5675 & $4200(74.0)$ & 1092 & $784(71.8)$ \\
\hline Older sibling, $n(\%)$ & 3943 & $2245(56.9)$ & 731 & $401(54.9)$ \\
\hline \multicolumn{5}{|l|}{ Maternal smoking, $n(\%)$} \\
\hline During pregnancy & 2020 & $92(4.6)$ & 316 & $55(17.4)$ \\
\hline During child's first 2 years & 5638 & $887(15.7)$ & 1078 & $391(36.3)$ \\
\hline Paternal smoking, $n(\%)$ & 5397 & $1072(19.9)$ & 994 & $330(33.2)$ \\
\hline Child exposed to smoke during first 2 years ${ }^{d}, n(\%)$ & 5675 & $1462(25.8)$ & 1095 & $502(45.8)$ \\
\hline Pets $^{\mathrm{e}}, n(\%)$ & 5695 & $1143(20.1)$ & 1101 & $264(24.0)$ \\
\hline Birthweight, gram, mean (SD) & 5625 & 3608 (552) range: $640-5560$ & 1072 & 3463 (705) range: $585-5960$ \\
\hline Birthweight < $2500 \mathrm{~g}, n$ (\%) & 5625 & $156(2.8)$ & 1072 & $88(8.2)$ \\
\hline Sex, male, $n(\%)$ & 5693 & $2798(49.2)$ & 1101 & $581(52.8)$ \\
\hline Lower respiratory tract infection within first year ${ }^{f}, n(\%)$ & 3217 & $333(10.4)$ & 606 & $78(12.9)$ \\
\hline Antibiotic treatment within first year, $n(\%)$ & 3746 & $756(20.2)$ & 695 & $163(23.5)$ \\
\hline Introduced to formula $<6$ months of age, $n(\%)$ & 5625 & $966(17.2)$ & 1093 & $972(88.9)^{9}$ \\
\hline Start of day-care $<12$ months of age, $n(\%)$ & 5051 & $394(7.8)$ & 930 & $65(7.0)$ \\
\hline
\end{tabular}

${ }^{a}$ :The numbers vary because of missing data

b: Yearly income in Norwegian krone based on postcode (range: 174967 to 319,333 for both groups)

: Mother, father or common child with parental reported asthma, ARC or eczema

${ }^{d}$ : Parental or indoor smoking; ${ }^{\text {e: }}$ Reported cat, dog or other furry pets

f: Pneumonia or bronchitis

g: questionnaire data indicates children started with formula after 6 months of age despite having been weaned before 6 months 
Table 4 Relation between breastfeeding duration and allergy-related diseases

\begin{tabular}{|c|c|c|c|c|c|c|}
\hline \multirow[b]{3}{*}{ Disease and age } & \multicolumn{4}{|c|}{ Duration of any breastfeeding $(N=6796)$} & \multirow{2}{*}{\multicolumn{2}{|c|}{ Odds ratio ${ }^{\mathrm{a}}(95 \% \mathrm{Cl})$}} \\
\hline & \multicolumn{2}{|c|}{$\geq 6$ months $(n=5695)$} & \multicolumn{2}{|c|}{$<6$ months $(n=1101)$} & & \\
\hline & $n^{\mathbf{b}}$ & $n(\%)$ & $n^{\mathbf{b}}$ & $n(\%)$ & Crude & Adjusted $^{\mathrm{c}}$ \\
\hline \multicolumn{7}{|l|}{ Asthma } \\
\hline 2 years (ever) & 5135 & $319(6.2)$ & 964 & $83(8.6)$ & $0.70(0.55,0.90)$ & $0.77(0.59,1.02)$ \\
\hline 6 years (current) & 3134 & $142(4.5)$ & 566 & $32(5.7)$ & $0.79(0.53,1.17)$ & $0.79(0.51,1.21)$ \\
\hline \multicolumn{7}{|l|}{ Wheeze } \\
\hline 2 years (ever) & 4981 & $1288(25.9)$ & 939 & $288(30.7)$ & $0.79(0.68,0.92)$ & $0.90(0.76,1.07)$ \\
\hline 6 years (current) & 3098 & $312(10.1)$ & 565 & $76(13.5)$ & $0.72(0.55,0.94)$ & $0.71(0.53,0.95)$ \\
\hline \multicolumn{7}{|l|}{ ARC } \\
\hline 2 years (ever) & 4690 & $268(5.7)$ & 871 & $86(9.9)$ & $0.55(0.43,0.71)$ & $0.65(0.49,0.86)$ \\
\hline 6 years (ever) & 2913 & $348(12.0)$ & 520 & 76 (14.6) & $0.79(0.61,1.04)$ & $0.77(0.58,1.04)$ \\
\hline \multicolumn{7}{|l|}{ Eczema } \\
\hline 2 years (ever) & 4994 & $853(17.1)$ & 931 & 145 (15.6) & $1.12(0.92,1.35)$ & $1.16(0.94,1.44)$ \\
\hline 6 years (current) & 3087 & $436(14.1)$ & 556 & $69(12.4)$ & $1.16(0.88,1.52)$ & $1.15(0.86,1.55)$ \\
\hline 6 years (ever) & 3071 & $613(20.0)$ & 554 & $97(17.5)$ & $1.17(0.93,1.49)$ & $1.18(0.92,1.53)$ \\
\hline
\end{tabular}

although the associations were weaker and no longer statistically significant: aOR $0.77(95 \%$ CI $0.59,1.02)$ and aOR 0.90 (95\% CI 0.53, 1.07), respectively. On the other hand, there remained a strong and statistically significant reduction in current wheeze at six years associated with longer breastfeeding (aOR 0.71, 95\% CI 0.53, 0.94). In absolute terms, we observed a $3.4 \%$ lower prevalence of wheeze at six years among children who had been breastfed for at least six months compared to those who were breastfed for a shorter period (10.1\% vs $13.5 \%)$ (Table 4). A strong and statistically significant reduction in crude OR was also observed for ARC at two years, which persisted after adjustment for possible confounders (aOR 0.65, 95\% CI 0.49, 0.86) and after exclusion of symptomatic children before six months of age (Suppl. Table S4, Additional File 1). A trend for a continued protective effect of longer breastfeeding was also seen for ARC at six years (aOR 0.77, 95\% CI 0.58, 1.04). For eczema and two and six years, although observed that longer breastfeeding duration was associated with slight increased odds of eczema in both the crude and adjusted analyses, these estimates were associated with wide confidence intervals and were not statistically significant (Table 4). When excluding children with symptoms of allergy-related disease before six months of age, the analyses showed similar trends for all outcomes, but with broader confidential intervals due to fewer eligible children (Suppl. Table S4, Additional File 1). Similarly, we saw approximately the same results in the analyses which excluded participants with more than one-year recall of breastfeeding (Suppl. Table S5, Additional File 1).
We also investigated the potential modifying effect of early introduction to infant formula by dividing the exposure status of children into three categories: those who were breastfed for less than six months, those who were breastfed for six months but also received infant formula before six months, and those who were breastfed for at least six months and did not receive infant formula during these first six months. For asthma, wheeze and eczema, we found that the risk of these allergy-related diseases was approximately the same among children breastfed for at least six months, regardless of whether they had been introduced to infant formula before six months of age (Suppl. Table S6, Additional File 1). On the other hand, the reduction in ARC observed among children with a longer duration of breastfeeding appears to be predominantly present in the subgroup that did not receive infant formula before six months of age. Specifically, the risk of ARC at two years of age was reduced in those breastfed without any infant formula up to six months (aOR 0.61, 95\% CI 0.46, 0.82) compared to those who were weaned before six months. Although a reduced risk was also seen for children who received supplementation with formula before six month and ongoing breastfeeding, the association was weaker and the estimate was less certain (aOR 0.78, 95\% CI 0.54, 1.15). Among six year olds, we observed a reduced risk of ARC for those who were breastfed without the introduction of formula up to at least six months (aOR 0.74, 95\% CI 0.55, 1.01), however the risk of ARC among children who had received formula before six months was approximately equal to those who were weaned before six months (aOR 1.04, $95 \%$ CI $0.71,1.51)$. 


\section{Timing of introduction to complementary foods and allergy-related disease}

Our data included information on the age of complementary food introduction for 3814 children. Among these infants, the mean age of introduction was 4.6 months (SD 1.3) and $26 \%$ were introduced to complementary foods at the age of six months or older. Later introduction was positively correlated to higher maternal education and nonsmoking parents (Table 5). The group that was introduced to complementary foods at six months or older was less likely to have received milk formula early in life. In this group, 933 of 993 (94\%) had been breastfed six months or more compared to 2269 of 2815 (81\%) in the early introduced group (Suppl. Table S3, Additional File 1).

Whilst, we found that late complementary food introduction (six months or older) was associated with a lower risk of wheeze at two years in the crude analyses, this association was weaker and no longer statistically significant in the adjusted model (aOR 0.85, 95\% CI 0.70, 1.05) (Table 6). Otherwise our investigations did not demonstrate any convincing associations between age of introduction to complementary foods and allergy-related diseases (Table 6 and Suppl. Table S7, Additional File 1).

Finally, we considered the influence of an overlapping period of breastfeeding and introduction to complementary foods on allergy-related disease development. On average, the children in the PACT study were breastfed for 6.2 months (SD 4.7) after the introduction of complementary foods and 2837 of 3485 (82\%) had a minimum of two months overlap. We found that the development of allergy-related disease was not convincingly associated with this overlap between breastfeeding and complementary food introduction (Suppl. Table S8, Additional File 1).

\section{Discussion}

Main results

Using prospective data from the PACT study, we found that a high proportion of women in central Norway continued breastfeeding beyond six months of age. However, the majority of families reported that they started

Table 5 Characteristics of the participants stratified according to age at introduction of complementary foods

\begin{tabular}{|c|c|c|c|c|}
\hline \multirow[b]{3}{*}{ Characteristics } & \multicolumn{4}{|c|}{ Age at introduction of complementary foods $(N=3814)$} \\
\hline & \multicolumn{2}{|c|}{$\geq 6$ months $(n=996)$} & \multicolumn{2}{|c|}{$<6$ months $(n=2818)$} \\
\hline & $n^{\mathrm{a}}$ & & $n^{\mathrm{a}}$ & \\
\hline Maternal age at birth, years, mean (SD) & 994 & 31.2 (4.2) range: $18.0-43.8$ & 2810 & 29.6 (4.5) range: $17.0-43.7$ \\
\hline Maternal education, $n(\%)$ & 596 & & 1409 & \\
\hline$<12$ years (less than high school) & & $17(2.9)$ & & $106(7.5)$ \\
\hline $12-16$ years (up to 4 years university) & & $288(48.3)$ & & $749(53.2)$ \\
\hline$>16$ years (more than 4 years university) & & $291(48.8)$ & & $554(39.3)$ \\
\hline Mean income ${ }^{\mathrm{b}}, \mathrm{NOK}$, mean (SD, range) & 952 & $256,368(28674)$ & 2699 & $254,101(29284)$ \\
\hline Family history of allergy ${ }^{c}, n(\%)$ & 995 & $768(77.2)$ & 2812 & $2147(76.4)$ \\
\hline Older sibling, $n(\%)$ & 995 & $588(59.1)$ & 2809 & $1570(55.9)$ \\
\hline \multicolumn{5}{|l|}{ Maternal smoking, $n(\%)$} \\
\hline During pregnancy & 538 & $10(1.9)$ & 1126 & $91(8.1)$ \\
\hline During child's first 2 years & 994 & $107(10.8)$ & 2807 & $597(21.3)$ \\
\hline Paternal smoking, $n(\%)$ & 981 & $170(17.3)$ & 2717 & $680(25.0)$ \\
\hline Child exposed to smoke during first 2 years ${ }^{\mathrm{d}}, n(\%)$ & 995 & $201(20.2)$ & 2817 & $923(32.8)$ \\
\hline Pets $^{\mathrm{e}}, n(\%)$ & 996 & $239(24.0)$ & 2818 & $633(22.5)$ \\
\hline Birthweight, gram, mean (SD, range) & 992 & 3583 (576) range: $1100-5500$ & 2808 & 3587 (577) range: $585-5370$ \\
\hline Birthweight < $2500 \mathrm{~g}, n(\%)$ & 992 & $31(3.1)$ & 2808 & $106(3.8)$ \\
\hline Sex, male, $n(\%)$ & 996 & $465(46.7)$ & 2818 & $1418(50.3)$ \\
\hline Lower respiratory tract infection within first year ${ }^{f}, n(\%)$ & 992 & $101(10.2)$ & 2809 & $307(10.1)$ \\
\hline Antibiotic treatment within first year, $n(\%)$ & 995 & $203(20.4)$ & 2812 & $689(24.5)$ \\
\hline Introduced to formula < 6 months of age, $n(\%)$ & 992 & $127(12.8)$ & 2810 & $897(31.9)$ \\
\hline Start of day-care $<12$ months of age, $n(\%)$ & 806 & $70(8.7)$ & 2281 & $200(8.8)$ \\
\hline
\end{tabular}

a: The numbers vary because of missing data

b: Yearly income in Norwegian krone based on postcode (range: 174967 to 319,333 for both groups)

: Mother, father or common child with parental reported asthma, ARC or Eczema

d: Parental or indoor smoking

e: Reported cat, dog or other furry pets

f: Pneumonia or bronchitis 
Table 6 Relation between age at introduction to complementary foods and allergy-related diseases

\begin{tabular}{|c|c|c|c|c|c|c|}
\hline \multirow[b]{3}{*}{ Disease and age } & \multicolumn{4}{|c|}{ Introduction to complementary foods $(N=3814)$} & \multirow{2}{*}{\multicolumn{2}{|c|}{ Odds ratio $^{\mathrm{a}}(95 \% \mathrm{Cl})$}} \\
\hline & \multicolumn{2}{|c|}{$\geq 6$ months $(n=996)$} & \multicolumn{2}{|c|}{$<6$ months $(n=2818)$} & & \\
\hline & $n^{\mathbf{b}}$ & $n(\%)$ & $n^{\mathbf{b}}$ & $n(\%)$ & Crude & Adjusted $^{c}$ \\
\hline \multicolumn{7}{|l|}{ Asthma } \\
\hline 2 years (ever) & 818 & $46(5.6)$ & 2328 & $143(6.1)$ & $0.91(0.65,1.28)$ & $0.92(0.64,1.34)$ \\
\hline 6 years (current) & 644 & $30(4.7)$ & 1699 & $75(4.4)$ & $1.06(0.69,1.63)$ & $1.18(0.75,1.86)$ \\
\hline \multicolumn{7}{|l|}{ Wheeze } \\
\hline 2 years (ever) & 797 & $173(21.7)$ & 2256 & $582(25.8)$ & $0.80(0.66,0.97)$ & $0.85(0.70,1.05)$ \\
\hline 6 years (current) & 637 & $70(11.0)$ & 1683 & $173(10.3)$ & $1.08(0.80,1.45)$ & $1.13(0.83,1.54)$ \\
\hline \multicolumn{7}{|l|}{ ARC } \\
\hline 2 years (ever) & 757 & $36(4.8)$ & 2127 & $133(6.3)$ & $0.75(0.51,1.09)$ & $0.88(0.60,1.30)$ \\
\hline 6 years (ever) & 603 & 76 (12.6) & 1591 & $203(12.8)$ & $0.99(0.74,1.31)$ & $1.09(0.81,1.47)$ \\
\hline \multicolumn{7}{|l|}{ Eczema } \\
\hline 2 years (ever) & 793 & $118(14.9)$ & 2267 & $360(15.9)$ & $0.93(0.74,1.16)$ & $0.98(0.77,1.24)$ \\
\hline 6 years (current) & 631 & $82(13.0)$ & 1670 & $224(13.4)$ & $0.96(0.74,1.26)$ & $0.96(0.72,1.28)$ \\
\hline 6 years (ever) & 629 & $113(18.0)$ & 1661 & $328(19.8)$ & $0.89(0.70,1.13)$ & $0.89(0.69,1.13)$ \\
\hline
\end{tabular}

a: For introduction to complementary foods at six months or older versus younger than six months

b. The numbers vary because of missing data

c: Adjusted for sex, maternal age, mean income, first degree relative with allergy, maternal smoking during the child's first two years and birthweight

introducing complementary foods before six months of age. Upon examining the relationship between these factors and allergy-related disease, we found that a longer duration of any breastfeeding is not conclusively associated with parental reported doctor-diagnosed asthma but may reduce the risk of wheeze at six years. We also observed an apparent protective effect of breastfeeding for at least six month and ARC at two years of age. At six years of age, we saw an ongoing tendency to reduced ARC among infants breastfed over six months. However, breastfeeding duration was not associated with eczema in our data, and neither the timing of introduction to complementary foods nor overlap between breastfeeding and complementary food introduction demonstrate any clear relation to asthma, wheeze, ARC or eczema.

Our results for asthma at six years are consistent with the findings of another large Norwegian cohort. Using data from the Norwegian Mother and Child Cohort Study (MoBa), Lossius et al. found that breastfeeding over one year did not appear to impart a protective effect against asthma compared to shorter durations [10]. Although they adopted a more stringent definition of asthma, their prevalence of $4.7 \%$ is comparable to our estimated prevalence of doctor diagnosed asthma. The findings of The Promotion of Breastfeeding Intervention Trial, the only cluster randomised trial on breastfeeding and asthma, also supports our results as they concluded that longer breastfeeding does not reduce asthma diagnosis at 6.5 years [8].

In contrast to these findings for asthma, both recent meta-analyses found a reduced risk of asthma/wheeze
[7] and recurrent wheeze [6] with a longer duration of total breastfeeding. A summary of the results from these meta-analyses for asthma/wheeze and the other allergyrelated diseases can be found in Table 7 . Both metastudies raised the suspicion of overstatement of the protective effects of breastfeeding on asthma/wheeze. Garcia-Larsen et al. [6] described their conclusion as having a very low grade of evidence. This was primarily due to failure to adjust for confounders, but also because of evidence of publication bias with many small studies reporting protective effects. Correspondingly, Lodge et al. [7] described weaker protective estimates in studies of higher methodological quality, particularly with respect to recall bias, but also in terms of controlling for confounders and the number of participants. Indeed, they found no association between breastfeeding and reduced asthma/wheeze when including only cohort studies. Whilst the risk of publication bias is evident, these meta-analyses of asthma and wheeze as a composite outcome, together with our own results, indicate that a longer duration of breastfeeding may have a prolonged protective effect primarily on symptomatic wheezing rather than doctor-diagnosed asthma. This may be due to both ongoing effects of early protection against respiratory infections as well as possible protection against infection also after weaning $[9,22]$. The results from the Millennium Cohort Study, United Kingdom, also demonstrate a clear dose-response effect of breastfeeding on early transient wheeze phenotype, but less certain relationships with late onset or persistent wheezing phenotypes [23]. 
Table 7 Association between breastfeeding duration and allergy-related disease in recent meta-analyses [6, 7]

\begin{tabular}{|c|c|c|c|c|c|c|}
\hline \multirow{2}{*}{$\begin{array}{l}\text { Condition } \\
\& \text { age }\end{array}$} & \multirow{2}{*}{$\begin{array}{l}\text { Comparison for } \\
\text { breastfeeding } \\
\text { duration }^{\mathrm{a}}\end{array}$} & \multicolumn{2}{|c|}{ All studies included } & \multicolumn{2}{|c|}{ Prospective cohort studies } & \multirow[t]{2}{*}{$\operatorname{Re}$} \\
\hline & & $\overline{N^{b}}$ & OR & $\bar{N}$ & OR & \\
\hline \multicolumn{7}{|l|}{ Wheeze } \\
\hline $0-4$ yo & $\mathrm{TBF}>5-7 \mathrm{mo}$ vs. $<5-7 \mathrm{mo}$ & 9 & $0.90(0.72,1.12)$ & 6 & $0.89(0.65,1.21)$ & {$[6]$} \\
\hline $5-14$ yo & $\mathrm{TBF}>5-7 \mathrm{mo} \mathrm{vs} .<5-7 \mathrm{mo}$ & 2 & $0.86(0.70,1.06)$ & 1 & $0.88(0.71,1.09)$ & {$[6]$} \\
\hline \multicolumn{7}{|c|}{ Recurrent wheeze } \\
\hline $0-4$ yo & $\mathrm{TBF}>5-7 \mathrm{mo} v \mathrm{vs}<5-7 \mathrm{mo}$ & 6 & $0.79(0.61,1.04)$ & 3 & $0.73(0.56,0.96)$ & {$[6]$} \\
\hline $5-14$ yo & $\mathrm{TBF}>5-7 \mathrm{mo} v \mathrm{vs}<5-7 \mathrm{mo}$ & 9 & $0.76(0.62,0.92)$ & 4 & $0.82(0.66,1.03)$ & {$[6]$} \\
\hline \multicolumn{7}{|l|}{ Asthma ${ }^{c}$} \\
\hline $5-18$ yo & More vs. Less & 29 & $0.90(0.84,0.97)$ & 13 & $0.94(0.80,1.11)$ & {$[7]$} \\
\hline \multicolumn{7}{|c|}{ Allergic rhinitis / rhinoconjunctivitis } \\
\hline $0-4$ yo & $\mathrm{TBF}>5-7 \mathrm{mo}$ vs. $<5-7 \mathrm{mo}$ & 2 & $0.81(0.64,1.02)$ & $--{ }^{d}$ & & [6] \\
\hline $0-5$ yo & More vs. Less & 6 & $0.79(0.63,0.98)$ & 2 & $0.91(0.74,1.13)$ & {$[7]$} \\
\hline $5-14$ yo & $\mathrm{TBF}>5-7 \mathrm{mo}$ vs. $<5-7 \mathrm{mo}$ & 1 & $1.14(0.75,1.72)$ & $-{ }^{d}$ & & [6] \\
\hline $5-18$ yo & More vs. Less & 9 & $1.05(0.99,1.12)$ & 4 & $1.12(1.02,1.24)$ & {$[7]$} \\
\hline \multicolumn{7}{|l|}{ Ezcema } \\
\hline $0-2$ yo & More vs. Less & 16 & $0.95(0.85,1.07)$ & 15 & $0.97(0.86,1.10)$ & {$[7]$} \\
\hline $0-4$ yo & $\mathrm{TBF}>5-7 \mathrm{mo}$ vs. $<5-7 \mathrm{mo}$ & 4 & $0.93(0.80,1.07)$ & 3 & $0.97(0.75,1.12)$ & {$[6]$} \\
\hline $2-18$ yo & More vs. Less & 20 & $1.09(0.99,1.20)$ & 6 & $1.36(0.90,2.06)$ & {$[7]$} \\
\hline $5-14$ yo & $\mathrm{TBF}>5-7 \mathrm{mo}$ vs. $<5-7 \mathrm{mo}$ & 2 & $1.35(1.07,1.72)$ & $-{ }^{d}$ & & {$[6]$} \\
\hline
\end{tabular}

TBF Total (any) breastfeeding

${ }^{a}$ Both meta-analyses report several comparisons based of different definitions of breastfeeding duration and exclusivity, here summarise the results from the comparison which would have included our own categorisation of breastfeeding duration. Meta-analysis by Lodge et al. [7] included a wide variety of studies comparing "more" vs "less" breastfeeding, whilst Garcia-Larsen et al. [6] completed separate meta-analyses for more specific comparisons of breastfeeding duration

${ }^{\mathrm{b}}$ Number of studies in the meta-analysis

"Lodge et al. include parental reports of wheeze as "asthma" in their meta-analysis

${ }^{\mathrm{d}}$ Only prospective cohort studies available for inclusion in these analyses

In our analyses, we also found that breastfeeding with a duration over six months tended to reduce the risk of ARC until school age. Lodge et al. found a similar risk reduction in their meta-analysis, but rightly pointed out that it is difficult to differentiate between viral and allergic rhinitis in young infants, such that the apparent protective effect of breastfeeding may be primarily against infectious rather than allergic rhinitis [7]. The lack of association between breastfeeding duration and eczema observed in our study is also consistent with the results from the meta-analyses by Lodge et al. and GarciaLarsen et al. [6, 7]. Furthermore, we found no statistically significant effects of age at introduction to complementary foods or continued breastfeeding while these foods were being introduced. This strengthens the conclusion from the meta-analyses by Garcia-Larsen et al. and Obaggy et al. which found no relation between age of introduction and allergy-related diseases [6].

\section{Strengths of the study}

The strengths of this study are its size, prospective design and comprehensive questionnaires. With information on approximately 6000 two-year-old and 3700 six-year-old children, our study represents one of the larger prospective cohort studies assessing the association between breastfeeding and eczema and ARC. Although there have been some larger cohort studies considering the influence of breastfeeding on asthma or wheeze, we also consider it a strength that all of these conditions have been examined together. In particular, the inclusion of both wheeze and doctor-diagnosed asthma allows us to examine the impact of the stringency of these definitions on the apparent association between breastfeeding and allergy-related disease. Furthermore, the prospective design minimises the risk of recall bias and allow us to consider the potential effect of reverse causality. In sensitivity analyses we considered both of these potential sources of errors, and found that our results were largely unaffected by the exclusion of participating families who reported weaning more than one year ago and when excluding children with symptom debut of any allergy-related disease before six months of age. With respect to recall bias, there is also evidence that recall of breastfeeding duration among 
Norwegian women is highly accurate even up to 20 years later [24].

Another strength of the PACT study is the detailed information found in the lifestyle questionnaires allowing us to control for potential confounding factors. As identified in the recent meta-analyses, incomplete adjustment for key confounders has been a major limitation of studies assessing the association between duration and exclusivity of breastfeeding, timing of complementary food introduction and the development of allergy-related diseases $[6,7]$. The confounding effect of family history of allergic disease and socio-economic status (SES) are considered particularly important in this context, both of which were included in our multivariable analyses together with other potential confounding factors. Family history of allergic disease in a first degree relative was included as covariate based on parent reports. Interestingly, we noted that family history was not significantly associated with either duration of breastfeeding or the age of introduction to complementary foods in our dataset. The challenges of controlling for SES are discussed in more detail in the limitations section, below. We also note that earlier studies have considered lower respiratory tract infections and antibiotic use within first year of life as possible confounders [7, 25, 26]. These variables have not been included as covariates in our analyses as we regard these to be potential mediators of the effect of breastfeeding on allergy-related disease. Adjustment for such mediating variables can bias the total effect estimates and should be avoided.

Previous studies have been criticised for evaluating allergic outcomes before breastfeeding termination and too early in childhood, when allergy-related disorders are harder to distinguish from infectious diseases [27]. By two years, almost all the children in the current study were weaned from breast milk and a persisting effect should be possible to detect. A diagnosis of asthma before five years may be misclassified infant wheezing and thus not an estimate of a true atopic condition. By examining the relations further at six years of age, our study allows for analyses of the time aspect in addition to account for the possible false diagnostics at two years.

\section{Limitations of the study}

The limitations to our study are the possibility of misclassification bias due to parental reported outcomes and residual confounding due to missing information or misclassification of potential confounders. There is also a risk of selection bias and a limited generalizability outside of Scandinavia. The parental reported outcomes are subjected to some degree of recall bias and are not as rigorous as physician examination or more objective measurements, like spirometry. In particular, our definitions of ARC and wheeze may identify infectious conditions rather than allergic ones. On the other hand, the reliability study on the questionnaires in PACT showed that the questions used for asthma and eczema underestimated, rather than overestimated, the prevalence of these conditions compared to the children's medical records [19]. Future studies should also consider using the Norwegian Prescription Database (NorPD), primarily for confirming the diagnosis of asthma. This was not possible for the current analysis since only $15 \%$ $(n=1022)$ of the included children were born after the establishment of this database in 2004. Reassuringly, we did not find evidence for recall bias upon excluding children with a recall period longer than one year. Residual confounding is another source of bias which we cannot exclude. Although our study accounts for many of the identified confounders, the PACT study did not include information on mode of delivery and mothers' body mass index. Caesarean delivery has been previously associated with both breastfeeding duration [28] and allergyrelated diseases [29]. Although there is some evidence that elective Caesarean delivery is particularly associated with lower rates and duration of breastfeeding [30], it is unclear if this association represents a causal biological effect or is confounded by factors such as intending to breastfeed which has been found to be lower among those who elect to deliver via Caesarean section [28]. Whilst there may be residual confounding because we have not taken mode of delivery into account, the national Caesarean section rate during the study period ranged from around 14 to $17 \%$ and approximately two thirds of these were emergency Caesarean sections [31]. Gestational age at birth is another such potential confounder that could not be included in the current analyses due to a high proportion of missing information. Nonetheless, we do not believe that this would have substantially influenced our results since gestational age is highly correlated with birthweight, which was included in all multivariate analyses. There is also a risk of residual confounding due to incomplete adjustment for SES. As described in the methods section, the average income for the postal code of residence was used as the only marker of SES due to incomplete information about parental educational attainment. We have conducted a number of assessments to confirm that this was our most suitable option. Reassuringly, we also found comparable results in the subgroup of families for which we have information on both parental education and average income for the postal code of residence. The use of this a postal code average income as an indicator is also in line with a Swedish study which suggested that neighbourhood purchasing power may be a useful special determinant of breastfeeding rates [32]. However, we acknowledge that there is a risk of non-differential misclassification bias due to the identification of group-level 
SES, particularly since lower SES appears to be associated with both lower rates of breastfeeding rates [33] and high rates of allergy-related disease [34] in Norway and the Nordic countries. It would be advisable that future studies use both parental educational attainment and family income to further reduce the risk of residual confounding. Studies in other countries may also need to consider other potential confounding factors, such as day-care attendance, which can influence both breastfeeding duration and may influence asthma and wheeze before 6-years of age [35]. Due to the generous parental leave in Norway, day-care attendance before one year of age is uncommon and does not represent a significant confounding factor.

In terms of the risk of selection bias, we know from a non-participant study that the participants in the PACT study are similar to the families who opted not to participate [19]. The breastfeeding rates found in this study are also comparable to a study conducted by the Norwegian Bureau of Statistics in 1998 which found that 80\% of infants were still breastfed at six months, yet more than $90 \%$ had already started some form of complementary food by six months [33]. Among those who submitted at least one lifestyle questionnaire in the PACT study, around a third were either lost to follow-up before completing the child healthcare questionnaire or missing information on breastfeeding and complementary food introduction. We do not have information about why participants did not complete these follow-up questionnaires. This is probably partially due to volunteer bias [36] and partially due to fluctuating interest in the study among the staff at the large number of community health centres who were responsible to handing out the follow-up questionnaires. The variability in recruitment also means that we do not know exactly how many families were invited to participate and this is another limitation of our study and makes it difficult to estimate the degree of potential selection bias. Nonetheless, despite the small differences seen between included and excluded participants in this study, we do not believe these differences affect our results and we consider the results to be generalizable, at least for other Nordic countries. In terms of generalisability beyond Scandinavia, the biological effects of breastfeeding should theoretically also be generalisable to other high incomes countries. Yet, it is difficult to know how the socio-political context affects the interplay between breastfeeding, allergy-related diseases, and confounding factors such as SES, so the observed relationships may be different in other countries and settings.

Finally, with the high proportion of women breastfeeding beyond six months, it is hard to study the risk for children who were not breastfed or breastfed for a shorter duration. Whilst, the extensive data on duration of breastfeeding and accurate age of first complementary foods are well suited to explore the impact of age at weaning and introduction, we did not have sufficient detail in the questionnaires to consider more nuanced infant feeding variations. For example, we do not have information regarding the extent of breastfeeding when the child was receiving a combination of breast and formula milk, or the quantity of the complementary foods after introduction. For this reason, we recommend cautious interpretation of the results of our sensitivity analysis considering the influence of introducing infant formula before six months.

\section{Conclusions}

We found a protective effect of longer breastfeeding duration on wheeze, but not on asthma, at six years. In addition, we saw a trend for a protective effect of longer breastfeeding on ARC up to school age. It remains unclear if these findings represent a protection against allergy mediated ARC, a prolonged effect of early defence against infection that persists after weaning. Our further analyses showed no conclusive associations between duration of breastfeeding, age at introduction to complementary foods and prevention of asthma, wheeze, ARC and eczema.

\section{Supplementary Information}

The online version contains supplementary material available at https://doi. org/10.1186/s13006-020-00352-2.

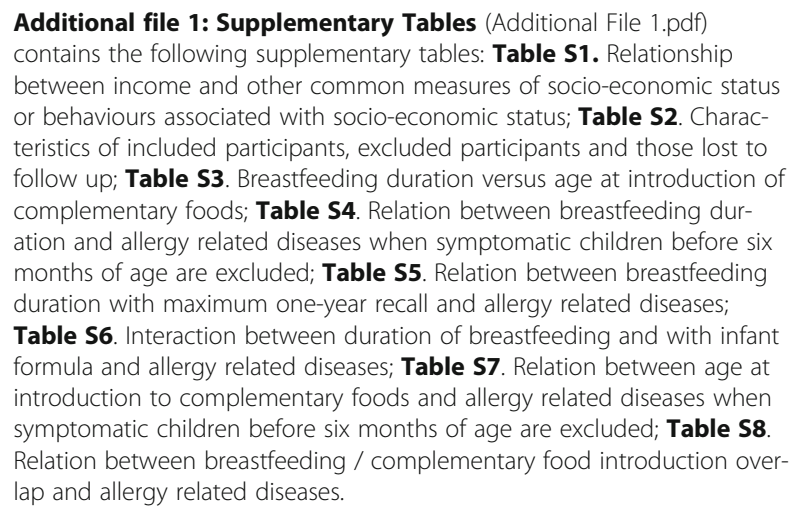

Abbreviations

aOR: Adjusted odds ratio; ARC: Allergic rhinoconjunctivitis; $\mathrm{Cl}$ : Confidence interval; ISAAC: International Study of Asthma and Allergies in Childhood; NOK: Norwegian kroner; OR: Odds ratio; PACT: Prevention of Allergy among Children in Trondheim; SD: Standard deviation; SES: Socio-economic status

\section{Acknowledgements}

Many thanks go to all the families and children who were study participants, the nurses, midwives and GPs for recruiting them, and the local authorities in Trondheim for their support in the planning and implementation of the PACT study. We would like to particularly acknowledge the contribution of Roar Johnsen and Ola Storrø in the establishment and running of the PACT study. 


\section{Authors' contributions}

TØ with collaborators conducted the study. TØ and MRS conceived the current study. LE and IG wrote the draft manuscript and did the statistical analyses. All the authors revised and approved the final article.

\section{Funding}

The PACT study was supported by The Norwegian Department of Health and Social Affairs (Helse- og omsorgsdepartementet) from 1997 to 2003; AstraZeneca Norge AS from 2000 to 2001; SINTEF Unimed in 1999; the Norwegian Research Council (Norges forskningsrådet) from 1999 to 2003; the Norwegian Medical Association; and the Norwegian University of Science and Technology. MRS position is funded by Central Norway Regional Health Authority (Helse Midt-Norge). The founding sources had no role in the collection, analysis, and interpretation of data; in the writing of the report; and in the decision to submit the article for publication.

\section{Availability of data and materials}

The datasets generated and/or analysed during the current study are not publicly available due to Norwegian privacy legislation but are available from the corresponding author on reasonable request.

\section{Ethics approval and consent to participate}

The Regional Committee for Medical and Health Research Ethics for Central Norway (2012/2123) approved this study. The Regional Committee for Medical Research Ethics for Central Norway approved the PACT study (Ref 120-2000). The study was granted a license by the Norwegian Data Inspectorate to process personal health data (2000/1475-2) and one of the parents signed a written informed consent form. The PACT study is registered in the Current Controlled Trials Registry: ISRCTN28090297.

\section{Consent for publication}

Not applicable.

\section{Competing interests}

The authors declare that they have no competing interests.

\section{Author details}

${ }^{1}$ Faculty of Medicine, Norwegian University of Science and Technology, NTNU, Trondheim, Norway. ${ }^{2}$ Department of Public Health and Nursing, Norwegian University of Science and Technology, NTNU, Trondheim, Norway. ${ }^{3}$ Clinic of Laboratory Medicine, St Olavs Hospital, Trondheim, Norway.

Received: 7 January 2020 Accepted: 10 December 2020 Published online: 06 January 2021

\section{References}

1. Asher MI, Montefort S, Bjorksten B, Lai CK, Strachan DP, Weiland SK, et al, Worldwide time trends in the prevalence of symptoms of asthma, allergic rhinoconjunctivitis, and eczema in childhood: ISAAC phases one and three repeat multicountry cross-sectional surveys. Lancet. 2006;368(9537):733-43.

2. Garcia-Aymerich J, Benet M, Saeys Y, Pinart M, Basagaña X, Smit HA, et al. Phenotyping asthma, rhinitis and eczema in MeDALL population-based birth cohorts: an allergic comorbidity cluster. Allergy. 2015;70(8):973-84.

3. Abbas AK, Lichtman AH, Pillai S. Cellular and molecular immunology. Philadelphia: Elsevier; 2018.

4. Dold S, Wjst M, von Mutius E, Reitmeir P, Stiepel E. Genetic risk for asthma, allergic rhinitis, and atopic dermatitis. Arch Dis Child. 1992;67(8):1018-22.

5. Matheson MC, Allen KJ, Tang ML. Understanding the evidence for and against the role of breastfeeding in allergy prevention. Clin Exp Allergy. 2012;42(6):827-51.

6. Garcia-Larsen V, lerodiakonou D, Jarrold K, Cunha S, Chivinge J, Robinson Z, et al. Diet during pregnancy and infancy and risk of allergic or autoimmune disease: a systematic review and meta-analysis. PLoS Med. 2018;15(2): e1002507.

7. Lodge CJ, Tan DJ, Lau MX, Dai X, Tham R, Lowe AJ, et al. Breastfeeding and asthma and allergies: a systematic review and meta-analysis. Acta Paediatr. 2015;104(467):38-53.

8. Kramer MS, Matush L, Vanilovich I, Platt R, Bogdanovich N, Sevkovskaya Z, et al. Effect of prolonged and exclusive breast feeding on risk of allergy and asthma: cluster randomised trial. BMJ. 2007;335(7624):815.
9. Li R, Dee D, Li CM, Hoffman HJ, Grummer-Strawn LM. Breastfeeding and risk of infections at 6 years. Pediatrics. 2014;134(Suppl 1):S13-20.

10. Lossius AK, Magnus MC, Lunde J, Stordal K. Prospective Cohort Study of Breastfeeding and the Risk of Childhood Asthma. J Pediatr. 2018; 195:182189.e182.

11. Waidyatillake NT, Dharmage SC, Allen KJ, Bowatte G, Boyle RJ, Burgess JA, et al. Association between the age of solid food introduction and eczema: a systematic review and a meta-analysis. Clin Exp Allergy. 2018;48(8):1000-15.

12. Du Toit G, Roberts G, Sayre PH, Bahnson HT, Radulovic S, Santos AF, et al. Randomized trial of peanut consumption in infants at risk for peanut allergy. N Engl J Med. 2015;372(9):803-13.

13. Perkin MR, Logan K, Bahnson HT, Marrs T, Radulovic S, Craven J et al. Efficacy of the Enquiring About Tolerance (EAT) study among infants at high risk of developing food allergy. J Allergy Clin Immunol. 2019; 144(6): 1606-1614.e1602.

14. Obbagy JE, English LK, Psota TL, Wong YP, Butte NF, Dewey KG, et al. Complementary feeding and micronutrient status: a systematic review. Am J Clin Nutr. 2019;109(Suppl_7):852s-71s.

15. Storro O, Oien T, Dotterud CK, Jenssen JA, Johnsen R. A primary health-care intervention on pre- and postnatal risk factor behavior to prevent childhood allergy. The Prevention of Allergy among Children in Trondheim (PACT) study. BMC Public Health. 2010;10:443.

16. Statens råd for ernæring og fysisk aktivitet. Anbefalinger for spedbarnsernæring [Recommendations for infant nutrition]. Oslo: Helsedirektoratet; 2001.

17. World Health Organization. Infant and young child feeding: World Health Organization. 2020. Available from: http://www.who.int/mediacentre/ factsheets/fs342/en/. Accessed 15 Dec 2020

18. Eiksund S, Gravaas B. Befolkningsendringer i Trondheim 2017. Tabell- og figursamling. [Population changes in Trondheim 2017. Table and figure collection.]. Available at: https://www.trondheim.kommune.no/ globalassets/10-bilder-og-filer/10-byutvikling/byplankontoret/statistikk/ folkemengde/befolkningsendringer-trondheim-2017.pdf [Accessed on: 12.11. 2018].

19. Oien T, Storro O, Johnsen R. Assessing atopic disease in children two to six years old: reliability of a revised questionnaire. Prim Care Respir J. 2008;17(3): 164-8.

20. Hasselberg PKJ, Agerlie K, Berre T, Johansen F. Hvor tjener folk i Trondheim mest? [Where in Trondheim do people earn the most?]. Available at: https:// www.nrk.no/trondelag/hvor-tjener-folk-i-trondheim-mest_-1.7344254 [Accessed on: 25.05.2018].

21. Galobardes B, Shaw M, Lawlor DA, Lynch JW, Davey SG. Indicators of socioeconomic position (part 1). J Epidemiol Community Health. 2006;60(1): 7-12.

22. Tromp I, Kiefte-de Jong J, Raat H, Jaddoe V, Franco O, Hofman A, et al. Breastfeeding and the risk of respiratory tract infections after infancy: the generation R study. PLoS One. 2017;12(2):e0172763.

23. Quigley MA, Carson C, Kelly Y. Breastfeeding and childhood wheeze: agespecific analyses and longitudinal wheezing phenotypes as complementary approaches to the analysis of cohort data. Am J Epidemiol. 2018;187(8): 1651-61.

24. Natland ST, Andersen LF, Nilsen TI, Forsmo S, Jacobsen GW. Maternal recall of breastfeeding duration twenty years after delivery. BMC Med Res Methodol. 2012;12:179.

25. Björkstén B, Aït-Khaled N, Innes Asher M, Clayton TO, Robertson C. Global analysis of breast feeding and risk of symptoms of asthma, rhinoconjunctivitis and eczema in 6-7 year old children: ISAAC phase three. Allergol Immunopathol (Madr). 2011;39(6):318-25.

26. Silvers KM, Frampton CM, Wickens K, Pattemore PK, Ingham T, Fishwick D et al. Breastfeeding protects against current asthma up to 6 years of age. J Pediatr. 2012; 160(6):991-996.e991.

27. Wold A. Why is there still confusion about the impact of breast-feeding on the risk of allergy development? Scand J Food Nutr. 2006;50(1):35-41.

28. Hobbs AJ, Mannion CA, McDonald SW, Brockway M, Tough SC. The impact of caesarean section on breastfeeding initiation, duration and difficulties in the first four months postpartum. BMC Pregnancy Child. 2016;16:90.

29. Bager P, Wohlfahrt J, Westergaard T. Caesarean delivery and risk of atopy and allergic disease: meta-analyses. Clin Exp Allergy. 2008;38(4):634-42.

30. Prior E, Santhakumaran S, Gale C, Philipps LH, Modi N, Hyde MJ. Breastfeeding after cesarean delivery: a systematic review and meta-analysis of world literature. Am J Clin Nutr. 2012;95(5):1113-35. 
31. Norwegian Insitute of Public Health. Årstabeller for Medisinsk fødselsregister 2010 - Fødsler i Norge [Annual report for medical birth register 2010 - births in Norway]. Editor: Bjørge T. Bergen; 2012. https://www.fhi.no/globalassets/ dokumenterfiler/rapporter/2010/rapport--arstabeller-for-medisinskfodselsregister-2010.pdf.

32. Almquist-Tangen G, Strömberg U, Holmén A, Alm B, Roswall J, Bergman S, et al. Influence of neighbourhood purchasing power on breastfeeding at four months of age: a Swedish population-based cohort study. BMC Public Health. 2013;13:1077.

33. Lande B. Spedkost 6 måneder: Landsomfattende kostholdsundersøkelse bland spedbarn i Norge [Infant diet at 6 months: Nation-wide dietary survey among infants in Norway]. Series Editor: helsedirektoratet S-o. Sosial- og helsedirektoratet. 2003. Oslo.

34. Grøholt E-K, Stigum H, Nordhagen R, Köhler L. Children with chronic health conditions in the Nordic countries in 1996 - influence of socio-economic factors. Ambul Child Health. 2001;7(3-4):177-89.

35. Swartz A, Collier T, Young CA, Cruz E, Bekmezian A, Coffman J, et al. The effect of early child care attendance on childhood asthma and wheezing: a meta-analysis. J Asthma. 2019;56(3):252-62.

36. Jordan S, Watkins A, Storey M, Allen SJ, Brooks CJ, Garaiova I, et al. Volunteer bias in recruitment, retention, and blood sample donation in a randomised controlled trial involving mothers and their children at six months and two years: a longitudinal analysis. PLoS One. 2013;8(7):e67912.

\section{Publisher's Note}

Springer Nature remains neutral with regard to jurisdictional claims in published maps and institutional affiliations.

Ready to submit your research? Choose BMC and benefit from:

- fast, convenient online submission

- thorough peer review by experienced researchers in your field

- rapid publication on acceptance

- support for research data, including large and complex data types

- gold Open Access which fosters wider collaboration and increased citations

- maximum visibility for your research: over $100 \mathrm{M}$ website views per year

At $\mathrm{BMC}$, research is always in progress.

Learn more biomedcentral.com/submissions 